\title{
PENERAPAN BERMAIN PERAN MELALUI TEKNIK IMPROVISASI BERBASIS SISIMIKA DI SMP NEGERI 1 PLOSO JOMBANG
}

\section{ROLE PLAYING IMPLEMENTATION THROUGH IMPROVISATION BASED ON SISIMIKA TECHNIQUES AT SMP NEGERI 1 PLOSO JOMBANG}

\author{
Khoirun Nisak $^{1 *}$, Purwati Anggraini ${ }^{2}$ \\ Pendidikan Bahasa Indonesia, Universitas Muhammadiyah Malang, Indonesia ${ }^{1,2}$ \\ khoirunnizak78@gmail.com ${ }^{1}$, poer1979@gmail.com ${ }^{2}$ \\ *penulis korespondensi
}

\begin{tabular}{|c|c|}
\hline Info Artikel & ABSTRAK \\
\hline $\begin{array}{l}\text { Sejarah artikel: } \\
\text { Diterima: } \\
\text { 14 Februari } 2021 \\
\text { Direvisi: } \\
3 \text { Juli } 2021 \\
\text { Disetujui: } \\
5 \text { Juli } 2021 \\
\text { Kata kunci: } \\
\text { bermain peran, } \\
\text { teknik improvisasi, } \\
\text { SISIMIKA (Persiapan, } \\
\text { Motivasi, dan } \\
\text { Mendalami Karakter) }\end{array}$ & $\begin{array}{l}\text { Tujuan penelitian ini adalah (1) mendeskripsikan proses bermain peran } \\
\text { dengan teknik improvisasi berbasis SISIMIKA (Persiapan, Motivasi, dan } \\
\text { Mendalami Karakter) dan (2) mendeskripsikan pengaruh kreativitas peserta } \\
\text { didik dalam bermain peran dengan teknik improvisasi berbasis SISIMIKA. } \\
\text { Metode penelitian ini pendekatan deskriptif. Jenis penelitian ini yaitu } \\
\text { kualitatif. Sumber data penelitian ini yaitu wawancara guru ekstrakurikuler } \\
\text { drama di SMP Negeri Ploso Jombang. Teknik analisis data dilakukan } \\
\text { dengan tahapan-tahapan berikut ini (1) reduksi data yaitu kegiatan } \\
\text { merangkum data, memilih dan memilah hal-hal pokok, dan memfokuskan } \\
\text { penemuan hal penting, (2) menyajikan data dalam bentuk teks naratif, (3) } \\
\text { membuat kesimpulan berdasarkan analisis data yang telah ditemukan. Hasil } \\
\text { penelitian ini menunjukkan (1) menerapkan proses bermain peran dengan } \\
\text { teknik improvisasi berbasis SISIMIKA (2) menerapkan kreativitas peserta } \\
\text { didik dalam bermain peran dengan teknik improvisasi berbasis SISIMIKA. }\end{array}$ \\
\hline Article Info & ABSTRACT \\
\hline $\begin{array}{l}\text { Keyword: } \\
\text { role plyaing, } \\
\text { improvisation } \\
\text { techniques, SISIMIKA } \\
\text { (Preparation, } \\
\text { Motivation, and } \\
\text { Deepening Character) }\end{array}$ & $\begin{array}{l}\text { The aims of this study are (1) to describe the process of role-playing with } \\
\text { improvisation techniques based on SISIMIKA (Preparation, Motivation, } \\
\text { and Character Exploration) (2) to describe the influence of students' } \\
\text { creativity in role-playing with improvisation techniques based on } \\
\text { SISIMIKA. This research method is a descriptive approach. This type of } \\
\text { research is qualitative. The data source of this research is the interview to } \\
\text { drama extracurricular teachers at SMP Negeri Ploso Jombang. The data } \\
\text { analysis technique was carried out with the following stages (1) data } \\
\text { reduction, namely activities to summarize data, select and sort out the main } \\
\text { points, and focus on finding important things, (2) presenting data in the form } \\
\text { of narrative text, (3) making conclusions based on analysis of the data that } \\
\text { has been found. The results of this study indicate (1) applying the role- } \\
\text { playing process with improvisation techniques based on SISIMIKA (2) } \\
\text { applying the creativity of students in role-playing with improvisation } \\
\text { techniques based on SISIMIKA. }\end{array}$ \\
\hline
\end{tabular}




\section{PENDAHULUAN}

Drama sebagai bentuk seni menceritakan sebuah kisah tentang dialog-dialog dan tokoh-tokoh melalui kombinasi antara dialog dan narasi yang dicetak semenarik mungkin. Kemudian, dipentaskan untuk dinikmati penonton sebagai hiburan. Selain sebagai hiburan, dampak positif drama bagi peserta didik tingkat Sekolah Menengah Pertama dapat melatih percaya diri sehingga berani tampil di depan umum.

$$
\text { Menurut Yurnelis }
$$

mengungkapkan bahwa sebuah karya sastra memiliki karakteristik yaitu berdimensi sastra dan seni petunjukan. Kedua dimensi tersebut dikolaborasikan agar menjadi sebuah karya sastra yang dapat dipentaskan secara sempurna. Persiapan bermain drama dirancang membutuhkan waktu panjang, persiapan tersebut dilakukan dengan cara latihan rutin menjelang pementasan drama. Latihan secara rutin diharapkan dapat melatih mental dan keterampilan peserta didik (Santosa, dkk, 2008). Latihan drama ini dilakukan untuk mengukur kematangan aktor dan memperhatikan kesalahan gerakan maupun diksi yang diucapkan. Diksi dapat diartikan sebagai pemilihan kata yang berpengaruh dalam bermain peran (Novianti, 2012).

Latihan bermain peran dilakukan dengan teknik improvisasi drama. Menurut Pratisca (2013) mengemukakan bahwa pembelajaran bermain peran dengan teknik improvisasi merupakan kompetensi dasar untuk mencapai target keterampilan seseorang. Sedangkan Susanto (2014) memapaparkan bahwa improvisasi drama berguna mengasah kepekaan aktor untuk mengatasi masalah yang terjadi saat pementasan. Kepekaan aktor terhadap bermain peran dapat ditinjau dari teknik improvisasi yang dilakukan.

Hamzah, (2000) berpendapat bahwa teknik improvisasi merupakan suatu gerakan maupun dialog yang dilakukan secara spontanitas. Menurut Kurniati (2011), spontanitas drama dapat melatih kesadaran aktor dalam berdialog maupun bernarasi seakanakan tidak melakukan kesalahan. Improvisasi drama cocok digunakan bagi peserta didik tingkat Sekolah Menengah Pertama karena dapat dikaterogikan sebagai aktor pemula. Improvisasi drama termasuk pementasan yang sederhana, mudah dipelajari, dan menyenangkan bagi peserta didik tingkat Sekolah Menengah Pertama. Improvisasi dalam bermain drama dapat mengasah daya kreativitas, inovatif, dan keterampilan dalam bermain peran.

Persiapan bermain peran membutuhkan waktu latihan yang serius, agar tidak terjadi kesalahankesalahan dalam gerakan maupun berdialog. Cara untuk mengantisipasi kejadian tersebut adalah bermain peran dengan teknik improvisasi berbasis SISIMIKA (Persiapan, Motivasi, dan Mendalami Karakter).

Pentingnya teknik improvisasi berbasis SISIMIKA yaitu digunakan ketika seorang aktor kehilangan daya fokus saat bermain peran. Maka hal yang dapat dilakukan aktor yaitu menerapkan teknik improvisasi. Bermain peran menggunakan teknik improvisasi dapat menumbuhkan kreativitas bermain peran dan mampu berperan dengan sempurna.

Pada penelitian ini, guru ekstrakulikuler SMP Negeri 1 Ploso Jombang sebelumnya melakukan pelatihan drama dengan cara meminta peserta didik menghafal naskah drama sesuai dengan perannya masing- 
masing. Tetapi hal tersebut sulit diterapkan pada peserta didik karena cara yang diterapkan dalam latihan bermain peran hanya sebatas menghafal naskah drama saja, sehingga peserta didik terpacu pada kalimat-kalimat naskah drama yang dihafalkan. Oleh sebab itu, guru ekstrakurikuler SMP Negeri 1 Ploso Jombang menerapkan latihan bermain drama dengan teknik improvisasi berbasis SISIMIKA.

Penelitian ini relevan terkait dengan teknik improvisasi drama yang pernah dilakukan oleh (Pratisca, dkk, 2013) dengan judul Pengembangan Strategi Suka Dokumen (Susun Kerangka, Dialog, Lakuan, dan Komentari) dalam Pembelajaran Bermain Peran dengan Cara Improvisasi untuk Peserta Didik SMP Kelas VII. Perbedaan penelitian dapat dilihat dari segi objek penelitian. Objek yang diteliti pada penelitian sebelumnya yaitu peserta didik kelas VII, sedangkan penelitian ini objek penelitiannya campuran dari kelas VII dan VIII.

Perbedaan kedua, fokus penelitian sebelumnya yaitu mengembangkan strategi susun kerangka, dialog, lakuan, dan komentari. Keterampilan bermain drama pada penelitian sebelumnya melakukan teknik pembelajaran kegiatan membaca naskah untuk menciptakan improvisasi dengan menulis kerangka cerita, sedangkan penelitian ini membahas tentang kreativitas peserta didik dengan cara menghafal naskah drama disertai teknik improvisasi bermain peran berbasis SISIMIKA.

Teknik improvisasi berbasis SISIMIKA merupakan teknik yang memiliki tiga cara dalam menerapkannya yaitu (1) persiapan bermain drama, (2) memotivasi aktor agar percaya diri, dan
(3) bermain drama dengan memberikan naskah drama serta melihat karakter tokoh. Sesuai uraian sebelumnya penelitian ini diharapkan dapat melengkapi kelemahan dan kekurangan dari penelitian-penelitian terdahulu.

Penggunaan teknik improvisasi berbasis SISIMIKA cocok digunakan untuk latihan drama maupun saat pementasan, karena teknik ini akan mempermudah aktor agar tidak kebingungan saat bermain peran. Adapun tujuan penelitian ini (1) mendeskripsikan proses bermain peran dengan teknik improvisasi berbasis SISIMIKA dan (2) mendeskripsikan pengaruh kreativitas peserta didik dalam bermain peran dengan teknik improvisasi berbasis SISIMIKA.

\section{METODE}

Pendekatan pada penelitian ini yaitu deskriptif. Jenis penelitian kualitatif. Sumber data penelitian ini melalui wawancara guru ekstrakulikuler drama di SMP Negeri 1 Ploso Jombang. Teknik pengumpulan data penelitian ini observasi di SMP Negeri 1 Ploso Jombang yang berhubungan langsung antara peneliti dengan narasumber guru ekstra kulikuler untuk mendapatkan data bukti dokumentasi. Teknik yang digunakan dalam bermain peran yaitu teknik improvisasi berbasis SISIMIKA. Rangkaian penelitian ini berdasarkan pendapat Miles dan Huberman (Sugiyono, 2013) analisis data dengan cara (1) reduksi data yaitu kegiatan merangkum data, memilih dan memilah hal-hal pokok, dan memfokuskan penemuan hal penting, (2) membuat data dalam bentuk teks naratif, (3) membuat kesimpulan berdasarkan analisis data yang telah ditemukan. 


\section{HASIL DAN PEMBAHASAN}

Pentingnya bermain drama bagi peserta didik SMP Negeri 1 Ploso Jombang berhubungan erat dengan permasalahan yang dihadapi peserta didik. Seperti sulit mengkreasikan dirinya di depan kelas dan tidak percaya diri jika berada dihadapan umum. Pentingnya penelitian ini bagi peserta didik di SMP Negeri 1 Ploso Jombang yaitu untuk mendeskripsikan pengaruh teknik improvisasi berbais SISIMIKA pada kreativitas bermain peran.

\section{Teknik Improvisasi Bermain Peran Berbasis SISIMIKA di SMP Negeri 1 Ploso Jombang}

Berdasarkan hasil wawancara guru ekstrakurikuler menunjukkan bahwa SMP Negeri 1 Ploso Jombang melakukan pementasan drama rutin setiap tahun. Pementasan drama biasa dipentaskan di lapangan sekolah. Drama yang dipentaskan pada acara wisuda purna siswa dan gebyar seni ulang tahun SMP Negeri 1 Ploso Jombang. Contoh pementasan drama yang pernah dipentaskan saat gebyar seni berjudul Nyai Dasimah, dan Anoman Obong. Pementasan drama dapat dinilai berjalan dengan lancar, teknik improvisasi yang yang dilakukan peserta didik sudah optimal. Hal itu terjadi karena setiap peserta didik dapat mengatasi masalahmasalah yang terjadi saat pementasan drama dengan improvisasi berbasis SISIMIKA.

Aktor didominasi oleh campuran peserta didik kelas VII dan VIII karena kelas tersebut dapat diarahkan dan fokus menguasai permainan drama, dibandingkan dengan kelas IX karena fokus ujian nasional. Pengajaran penggunaan teknik improvisasi berbasis SISIMIKA diterapkan oleh guru ekstra kulikuler dengan cara sebagai berikut. a. Persiapan bermain peran

Persiapan bermain peran dilakukan secara telaten dan teliti. Mulai dari mempersiapkan pelatihan pemilihan aktor, latihan membaca dialog dalam naskah, latihan rutin, dan latihan menjelang pemestasan. Hal yang perlu diperhatikan oleh aktor saat bermain peran yaitu menekankan bahasa, gerak tubuh, intonasi, dan mimik.

Adanya persiapan matang dalam bermain peran yaitu supaya aktor mudah menghafalkan naskah, kemudian naskah tersebut diimprovisasikan. Selain itu hal yang perlu dipersiapkan secara keseluruhan adalah tata rias, tata busana, tata lampu, tata suara, dan properti untuk menyempurnakan sebuah pementasan drama. Hal ini sesuai dengan pendapat Bawana (2017) bahwa tahap persiapan drama dilakukan dengan empat cara yaitu (1) pemilihan tim produksi, (2) pemilihan naskah, (3) pemilihan pemain, (4) merekam dubbing. Perbedaan dengan data yang diperoleh oleh Bawana (2017) bahwa pada persiapan bermain drama meliputi tata rias, tata busana, dan tata lampu tidak dilakukan pada permulaan persiapan bermain peran.

\section{b. Memotivasi aktor percaya diri}

Menurut Surya (Utami, 2017) mengemukakan bahwa percaya diri merupakan bagian penting dalam mengembangkan kepribadian aktor. Maka memotivasi peserta didik dalam bermain peran biasa ditanamkan oleh guru ekstrakulikuler SMP Negeri 1 Ploso Jombang. Selain itu, rasa percaya diri yang tertanam juga berasal dari motivasi teman. Menumbuhkan rasa percaya diri bermain peran dapat membantu peserta didik berani tampil di depan 
umum. Adanya rasa percaya diri yang tinggi peserta didik dapat menumbuhkan kreativitas, mengkreasikan vokal, gerak tubuh, dan improvisasi drama dengan baik. Oleh sebab itu memotivasi percaya diri aktor juga menjadi peran penting dalam hal ini.

c. Melihat karakter aktor dalam bermain peran

Memberikan naskah drama dengan memperhatikan karakter aktor akan membantu seorang aktor dalam bermain peran. Pemilihan karakter aktor secara matang juga dapat membantu guru ekstrakulikuler dalam pengajaran bermain peran. Pemilihan karakter aktor oleh guru ekstrakulikuler dilihat dari keseharian yang telah diamati, sehingga peserta didik yang telah dipilih menjadi aktor dapat mengekspresikan diri dan menguasai karakter aktor. Hal ini juga sesuai dengan pendapat Suhariyadi dalam Bawana (2017) yang mengemukakan bahwa mendalami karakter aktor dalam bermain peran diharapkan mampu memilih aktor yang sesuai dengan karakter pada naskah. Pemilihan aktor dipertimbangkan dari aspek bentuk tubuh, kecerdasan, dan panca indra.

Memperhatikan karakter masing-masing aktor juga dapat menyempurnakan sebuah pementasan drama, karena aktor dapat menguasai karakter yang dimainkannya, sehingga dapat mengimprovisasikan drama dengan kreasinya yaitu improvisasi gerak tubuh maupun dialog saat pementasan drama. Berikut pementasan drama dengan menggunakan teknik improvisasi berbasis SISIMIKA yang pernah dipentaskan oleh peserta didik SMP Negeri 1 Ploso Jombang:

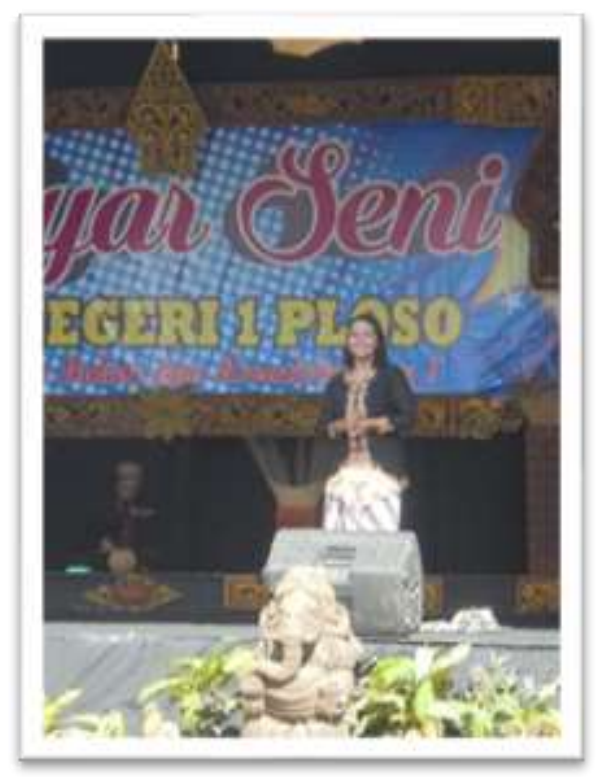

Gambar 1. Pementasan Drama Gebyar Seni

(Nyai Dasimah)

Pementasan drama yang bertempat di SMP Negeri 1 Ploso Jombang dilakukan pada acara gebyar seni yaitu saat ulang tahun SMP Negeri 1 Ploso Jombang. Drama berjudul Nyai Dasimah dipentaskan dengan teknik improvisasi berbasis SISIMIKA (Persiapan, Motivasi, dan Mendalami Karakter). Pementasan ini diperankan oleh aktor Nyai Dasimah dengan aktor dibelakangnya yaitu Mbah Dukun. Keduanya bermain peran di atas panggung secara bersamaan, tetapi seperti tidak memandang dan tidak mengerti satu sama lain bahwa kedua aktor tersebut dalam satu tempat.

Teknik improvisasi berbasis SISIMIKA (Persiapan, Motivasi, dan Mendalami Karakter) dilakukan keduanya nyaris sempurna. Nyai Dasimah tersenyum dalam pementasan drama melihat penonton. Sedangkan aktor yang berperan sebagai Mbah Dukun dengan khusuknya membaca 
mantra serta menggerakkan tangan di atas kendi yang menggambarkan tercapainya mantra yang dipanjatkan.

Penggunaan teknik improvisasi berbasis SISIMIKA yang dilakukan Mbah Dukun dalam menggerakkan tangannya sudah sesuai dengan latihanlatihan sebelumnya. Meskipun demikian, terkadang gerakan tangan Mbah Dukun antara latihan dan pementasan sedikit berbeda. Tetapi dengan menggunakan teknik improvisasi berbasis SISIMIKA, pergerakan tangan Mbah Dukun tidak terlihat melakukan kesalahan seperti tersenggal-senggal. Hal ini Mbah Dukun telah merealisasikan teknik improvisasi secara spontan untuk menghasilkan pergerakan mirip seperti Mbah Dukun sungguhan.

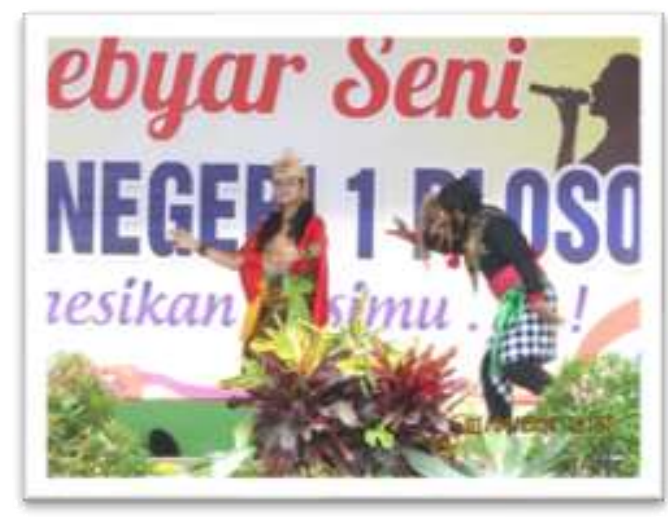

Gambar 2. Pementasan Drama Gebyar Seni (Anoman Obong)

Drama yang berjudul Anoman Obong yang dipentaskan pada saat gebyar seni, yaitu memperingati hari ulang tahun SMP Negeri 1 Ploso Jombang dengan mempersembahkan sebuah pementasan drama yang dilakukan rutin setiap tahunnya.

Berdasarkan hasil observasi melalui wawancara guru ekstrakulikuler bahwa pementasan drama Anoman Obong pada saat itu Shinta sedang berdialog. Aktor Shinta saat bermain drama terlalu fokus berdialog, sehingga lupa bahwa langkah selanjutnya adalah menari. Adanya ketidakfokusan tersebut, Anoman melakukan teknik improvisasi berbasis SISIMIKA dengan cara berdialog sambil menari dibelakang Shinta, walaupun saat itu Shinta tetap menari. Kemudian Shinta melakukan improvisasi drama dengan menari menghadap Anoman dan melanjutkan berdialog. Penggambaran cerita yang disuguhkan pada pemetasan drama Anoman Obong dapat dikategorikan sebagai perpaduan antara bermain peran dan menari. Teknik improvisasi berbasis SISIMIKA dilakukan oleh kedua aktor dengan cara Anoman membantu Shinta agar mengingat lagi alur naskah yang telah dibuat. Menerapkan kerjasama yang kuat antar aktor dapat mengatasi kesalahankesalahan yang akan terjadi.

Hal yang dilakukan selanjutnya setelah pementasan drama yaitu evalusasi. Saat evaluasi guru ekstrakurikuler memberikan masukan serta menilai kekurangan pementasan, kemudian diberikan arahan terkait dengan kesalahan yang dilakukan agar kedepannya tidak terulang lagi. Guru ekstrakulikuler juga mengucapkan selamat kepada peserta didik, karena telah bekerja keras mensukseskan pementasan drama, mulai dari persiapan hingga akhir acara pementasan.

Pementasan drama dalam acara ulang tahun SMP Negeri 1 Ploso Jombang oleh peserta didik dapat menampilkan sebuah pementasan drama yang mengesankan. Pementasan drama tersebut berhasil menyita perhatian penonton, karena peserta didik mampu berkreasi dan berinovasi menerapkan teknik improvisasi berbasis SISIMIKA. 
Pengaruh Kreativitas Bermain Peran dengan Teknik Improvisasi Berbasis SISIMIKA Bagi Peserta Didik SMP Negeri 1 Ploso Jombang

Berdasarkan hasil wawancara guru ekstrakurikuler, peserta didik SMP Negeri 1 Ploso Jombang mengemukakan bahwa bermain drama dapat melatih kompetensi membaca, menulis, menyimak, dan berbicara. Selain itu bermain drama juga dapat berpengaruh untuk menumbuhkan kreativitas dan tingkat produktif dalam pementasan yang sederhana. Bermain drama dapat membantu peserta didik dalam menghayati karakter emosi anak, Ampera (dalam Amri dkk, 2016). Menurut Nasution (2009) drama tidak terbatas pada tataran teks saja, melainkan juga merupakan seni pementasan dimensi sastra. Bermain peran disebut juga dengan melisankan dan memerankan tokoh sebuah cerita yang ada di dalam cerita drama sesuai dengan watak masing-masing tokoh (Susanto, 2014).

Proses bermain drama dengan teknik improvisasi berbasis SISIMIKA dibagi menjadi menjadi tiga fase yaitu (1) munculnya ide saat lupa naskah drama saat berlangsungnya bermain drama dipentaskan, (2) saat latihan harus menyiapkan matang-matang bahan atau properti yang digunakan untuk dipakai saat bermain drama berlangsung, dan (3) ketika pementasan drama dimulai secara tiba-tiba muncul inspirasi dalam dirinya. Pengajaran peran bagi peserta didik tingkat SMP Negeri 1 Ploso Jombang khususnya drama dapat berpengaruh terhadap kreativitas peserta didik untuk menumbuhkan rasa percaya diri.

Dampak bermain drama peserta didik SMP Negeri 1 Ploso Jombang dilakukan secara rutin dan dilakukan lebih rutin lagi ketika menjelang pementasan drama. Peserta didik SMP Negeri 1 Ploso Jombang dalam memerankan sebuah aktor telah sesuai dengan karakter aktor yang diperankan. Memberikan kesempatan bagi peserta didik SMP Negeri 1 Ploso Jombang bermain drama dengan teknik improvisasi berbasis SISIMIKA mengarahkan peserta didik terhadap pengalaman untuk menumbuhkan kreativitas bermain peran dalam sebuah pementasan.

\section{PENUTUP}

Berdasarkan hasil dan pembahasan melalui observasi guru ekstrakulikuler dapat disimpulkan bahwa bermain peran di SMP Negeri 1 Ploso Jombang dengan menggunakan teknik improvisasi berbasis SISIMIKA sudah mulai berkembang dan meningkat. Hal ini disebabkan karena peserta didik teliti dan rajin berlatih drama. Peserta didik dapat mengimplementasikan teknik improvisasi berbasis SISIMIKA dengan baik. Penggunaan teknik improvisasi berbasis SISIMIKA dapat mempermudah peserta didik dalam menumbuhkan kreativitas bermain peran sesuai dengan karakternya masing-masing.

Hasil penelitian ini yaitu (1) bermain peran dengan menggunakan teknik improvisasi berbasis SISIMIKA dapat menumbuhkan daya aktif, inisiatif, kreatif dan inovatif, dan memperlancar proses peserta didik dalam bermain peran. (2) mendeskripsikan pengaruh kreativitas dan percaya diri peserta didik terhadap masalah yang dihadapi. Oleh sebab itu pementasan drama dengan teknik improvisasi berbasis SISIMIKA menghasilkan sebuah kesempurnaan pementasan dan kreativitas peserta didik. 


\section{DAFTAR PUSTAKA}

Amri, U. dkk. (2016). Pengaruh Penggunaan Teknik Bermain Drama Melalui Teater Tradisional Randai Berbasis Kepercayaan Diri Terhadap Kemampuan Apresiasi Drama. Jurnal Pendidikan Dasar, 8.

Bawana, K. A. dkk. (2017). Proses Produksi Pementasan Drama Teater Angin SMA Negeri 1 Denpasar. e-Journal Universitas Pendidikan Ganesha.

Hamzah, A. (2000). Pengantar Bermain Drama. Bandung: CV Rosda.

Kurniati, N. (2011). Keaktifan Teknik Improvisasi Dalam Pembelajaran Bermain Peran Peserta didik Kelas VIII SMP Negeri 1 Parakan Kabupaten Temanggung. Universitas Negeri Yogyakarta.

Nasution, I. M. (2009). "Semar Gugat" Dalam Telaah Tokoh: Sebuah Model Pemaknaan Naskah Drama. Jurnal Pendidikan Bahasa Sastra Dan Seni, 10.

Novianti, L. (2012). Peningkatan Keterampilan Bermain Drama Melalui Teknik Pembelajaran Roating Roles Pada Peserta didik Kelas VIII D SMP N 2 Sentolo Kulon Progo. Universitas Negeri Yog yakarta.

Pratisca, dkk. (2013). Pengaruh Strategi Suka Dokumen (Susun, Kerangka, Dialog, Lakuan dan Komentari) dalam
Pembelajaran Bermain Peran dengan Cara Improvisasi Drama untuk Kelas VIII. Journal Online UM.

Santosa, E. (2008). Seni Teater Jilid I: Untuk Sekolah Menengah Kejuruan. Jakarta: Departemen Pendidikan Nasional.

Sugiyono. (2013). Metode Penelitian Pendidikan: Pendekatan Kualitatif Kuantitatif dan $R \& D$ (16th ed). Bandung: ALFABETA.

Susanto, H. (2014). Kemampuan Bermain Peran Dengan Teknik Improvisasi Dalam Drama Pengorbanan Seorang Ibu Siwa Kelas VIII Sekolah Menengah Pertama Pelita Nusantara Tanjungpinang. Artikel EJournal.

Utami， D. dkk. (2017). "Kapsul Motovasi" Meningkatkan Kepercayaan Diri Mahasiswa. Prosiding SEMNAS Penguatan Individu di Era Revolusi Informasi

Yurnelis. (2012). Peningkatan Keterampilan Menulis Naskah Drama Melalui Pendekatan Pembelajaran Konstektual Peserta didik Kelas VIII RBSISMP N 12 Padang. Jurnal Pendidikan Bahasa Sastra Dan Seni, 13. 